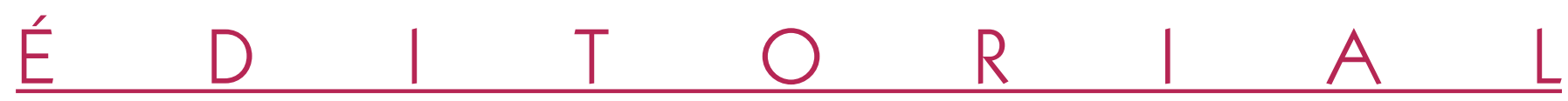

\title{
Le sourire est un devoir social ${ }^{1}$
}

\begin{abstract}
Al'heure où l'homme s'installe dans une salle obscure, il redécouvre au visionnage des succès du box-office les charmes de l'orthodontie. Imaginez un « Jacquouille la fripouille " officiant comme "majordome " loin de ses écuyers moyenâseux, Tom Cruise conservant sa "classe 2 » dans Top Gun, ou Natalie Portman dansant avec des dents jaunes dans Black Swan ... Même Joey Starr se joue de sa dent en or... Les stars du grand écran se doivent de présenter des dents blanches et un sourire éclatant «à l'américaine».
\end{abstract}

Mais désormais, nous sommes tous des stars, au sein de notre entreprise, de notre tribunal, de notre espace social ou même de la vie quotidienne. Le constat est on ne peut plus clair, l'ère contemporaine est à l'esthétique, et notamment à l'esthétique dentaire : éclaircissement, facettes, implants, anti-âse... Le sourire est devenu un devoir social.

L'esthétique du sourire, des dents bien aliznées, les professionnels de l'orthopédie dento-faciale savent faire. Mais parfois ces attentes deviennent exigences, les demandes extravagances, les délais immédiats..., tant et si bien qu'à force d'être consommateur de soins, les patients viennent à en oublier que les professionnels de santé sont des soignants, et non des couturiers, soumis à l'aléa de la nature.

Les litiges naissent ainsi souvent de l'incompréhension entre le professionnel, prestataire de service, et le patient, consommateur, entre ce qui relève du soin et du bien-être d'une part, et ce qui relève de l'esthétisme et du confort d'autre part.

\footnotetext{
${ }^{1}$ Stéphane Gsell (1864-1932)
} 
Le premier est soumis à une obligation dite de moyens, là où le second répond d'une oblization de résultats, le premier n'est pas soumis à la TVA, le second y sera bientôt assujetti, le premier soigne, le second peut mutiler, le premier est pris en charge au moins partiellement par les complémentaires, le second reste à la charge de l'assuré, le premier bénéficiera de la clémence du magistrat, le second prêtera à un contentieux sans concession...

C'est en ce sens que les magistrats ont rappelé récemment que les actes de soins n'étaient soumis qu'à une obligation de moyens. L'acte médical supporte un aléa, et l'échec de traitement est toléré, si le praticien a effectué des soins conformément aux données acquises de la science. En revanche, l'esthétique par son caractère facultatif reste soumise à une obligation de moyens très renforcés.

C'est en ce sens aussi que, l'information, si elle reste orale, est désormais renforcée, avec un délai de réflexion supplémentaire et une information financière écrite, afin de s'assurer de la bonne compréhension du patient.

Si la «faute » technique redevient excusable, et le praticien un technicien, un homme de l'art, c'est au profit de la garantie d'une bonne compréhension et du libre choix du traitement par le patient.

Si le sourire est un devoir social, et l'orthodontie y contribue, il convient de ne pas oublier que la communication et le dialogue restent les bases de la paix sociale.

Laurent Delprat

Avocat à la cour

Docteur en droit

Chargé d'enseignement

Les opinions émises n'engagent que leurs auteurs. 